\title{
TUMPÁ: A CRIAÇÃO DE UM RECURSO DIGITAL PARA ENSINO DE MÚSICA NA ESCOLA
}

\author{
$\underline{\text { Artur Araújo Silva }}$; Bruno Westermann²; \\ 1. Bolsista PROBIC/UEFS, Graduando em Licenciatura em Música, Universidade Estadual de Feira de Santana, e- \\ mail: artur araujo silva@hotmail.com \\ 2. Orientador, Departamento de Letras e Artes, Universidade Estadual de Feira de Santana, e-mail: \\ brwestermann@gmail.com
}

PALAVRAS-CHAVE: educação musical; tecnologias no ensino de música; educação

\section{INTRODUÇÃO}

A pesquisa a seguir trata de um memorial descritivo da criação do recurso digital TumPá ${ }^{1}$, um canal de conteúdo em vídeo do Youtube desenvolvido para o ensino e a prática da percussão corporal em aulas de música na escola. Neste trabalho, apresentaremos um protótipo de uma videoaula, como forma de testarmos o formato que será adotado em futuras produções do canal. Além disso, o projeto conta com um registro das gravações da criação do protótipo, acompanhado de um plano de aula, no qual descrevemos as possibilidades da sua aplicação em uma atividade prática com a utilização do recurso TumPá.

\section{MATERIAL E MÉTODOS}

A proposta inicial desta pesquisa foi que o produto TumPá fosse desenvolvido baseado no perfil de uso deste tipo de recurso por estudantes e professores, além de demonstrar as possibilidades da sua aplicação na escola. Em vista disso, seu desenvolvimento se deu a partir de dados coletados em uma escola de Educação Básica Pública de Feira de Santana, sobre sua infraestrutura tecnológica disponível sobre o perfil de uma turma no que diz respeito ao acesso a recursos audiovisuais na internet. Além disso, foram coletados dados sobre o perfil de acesso. Como instrumentos de coleta de dados, foram utilizados um roteiro de caracterização, questionários e observações na escola, cujos resultados fundamentaram as decisões da criação do recurso.

A pesquisa de campo aconteceu na instituição de ensino Centro Integrado de Educação Assis Chateaubriand localizada no município de Feira de Santana/BA, bairro Sobradinho, no período em que cumpri minhas atividades como professor estagiário dentro do componente curricular Estágio Supervisionado III, nos meses de Outubro a Novembro de 2016.

Nesse período, foram coletados dados da infraestrutura tecnológica da escola e dos alunos da turma do $7^{\circ}$ Ano $\mathrm{C}$, durante as aulas de música lecionadas por mim no período da pesquisa de campo. As informações sobre o perfil dos estudantes foram coletadas mediante a aplicação de um questionário como objetivo de obter dados que

\footnotetext{
${ }^{1}$ Link para o canal: https://www.youtube.com/channel/UCQqvk1nM1BXceufONr2XPUg. Acessado em: 05 de Agosto de 2017.
} 
apontassem as características de um provável perfil de usuários do recurso TumPá, além de indicar possíveis modificações no formato final do produto. Essas mudanças teriam como objetivo a criação de uma interface mais acessível, capaz de funcionar perfeitamente nos dispositivos eletrônicos utilizados pelos estudantes e aproximar as aplicações do recurso aos interesses do seu público alvo.

Foi criado um roteiro de caracterização foi criade para servir de instrumento para a coleta de dados desses espaços, visando identificar fatores que influenciariam na construção do formato final do TumPá. A partir desse roteiro foram coletadas informações sobre a infraestrutura da escola, com o intuito de obter informações sobre os espaços tecnológicos e seus recursos disponíveis. Foram listados alguns ambientes onde existia a presença de equipamentos eletrônicos e visitas a estes locais foram programadas em acordo com a instituição anfitriã.

\section{RESULTADOS E/OU DISCUSSÃO (ou Análise e discussão dos resultados)}

A partir da coleta de dados, foi possível traçar um perfil do público alvo para o uso deste tipo de recurso por estudantes e professores, além de demonstrar as possibilidades da sua aplicação na escola. As observações feitas em campo a partir dos dados obtidos pelo roteiro de caracterização e também, pelo Questionários de Pesquisa dos Estudantes ${ }^{2}$ foram imprescindíveis para construção e melhorias do recurso. Primeiramente, notou-se que apesar dos espaços tecnológicos existentes no ambiente escolar possuírem os recursos necessários para utilização de material audiovisual online, em alguns casos esses espaços podem estar passando por reformas ou terem problemas na sua infraestrutura que impossibilitam o seu uso. Como, por exemplo, foi observado no Laboratório de Informática da escola investigada que possuía computadores e sistema de internet, mas passava por reformas técnicas em seus equipamentos, o que tornava seu espaço inacessível para aulas envolvendo estes recursos.

Diante dessa situação vivida no estudo de campo, foi possível planejar contramedidas para facilitar o acesso ao recurso TumPá, centrando o desenvolvimento do projeto para utilização em dispositivos móveis, o que facilitaria aos professores a obtenção e aplicação da ferramenta. A depender da plataforma em que fosse hospedado o TumPá, foi pensada uma maneira de disponibilizar o seu conteúdo para downloand, esperando dar mais alternativas de acesso aos seus usuários. Além disso, através da análise do Questionário de Pesquisa dos Estudantes foi possível constatar um grande uso de dispositivos eletrônicos por partes dos alunos, principalmente de smartphones. Sendo que os dados levantados apontam para um grande interesse por parte desses estudantes no uso de aplicativos e plataformas digitais, como por exemplo o Youtube. $\mathrm{O}$ que levou a conclusão que dentro do ambiente da internet haveria maiores chances desses jovens acessarem o conteúdo desenvolvido se esse fosse acessível para smartphones e tablets, o que levou a uma necessidade ainda maior da ferramenta se adequar aos sistemas mobile.

Portanto, essa análise permitiu compreender como a ferramenta TumPá se adequaria ao ambiente escolar, partindo das necessidades diárias dos professores e da

\footnotetext{
${ }^{2}$ Questionário de Pesquisa dos Estudantes disponível em: https://goo.gl/UzTgCR. Acessado em: 5 de Agosto de 2017.
} 
sua infraestrutura tecnológica. E como o recurso alcançaria o interesse dos alunos, tão familiarizados com os sistemas de internet e produtos eletrônicos. Sendo assim essa primeira etapa, serviu para definir características do formato do recurso TumPá e "acessórios" necessários para melhorar o desempenho das suas aplicações.

\section{CONSIDERAÇÕES FINAIS}

A produção desta pesquisa mostrou-se muito promissora no campo das tecnologias para educação musical e ensino-aprendizagem de música. A criação de um produto no formato audiovisual além de adentrar esse campo de estudo, desperta o interesse para o entendimento de outras ferramentas que são necessárias para o desenvolvimento de um produto eletrônico com aplicações de ensino.

São necessários conhecimentos de diversas áreas como educação musical, computação, design gráfico e pedagogia para a construção do recurso e para criação do seu conteúdo, de forma que este contemple o objetivo desejado e mantenha o seu valor pedagógico. Dessa forma, o TumPá foi criado com objetivo de fornecer conhecimento de maneira intuitiva e rápida. Podendo funcionar em diversos dispositivos e formatos eletrônicos.

Ao trabalhar com plataformas já existentes como o Youtube, foi possível criar uma ferramenta de fácil acesso, interessante para seus usuários e que pudesse funcionar dentro dos seus pressupostos pedagógicos. Apesar de ser um recurso eletrônico, o formato de videoaula empregado no TumPá permite trabalhar a percepção e o cognitivo do aluno, além da corporalidade e ritmo. Podendo, em certo ponto substituir a falta de outras ferramentas, como por exemplo instrumentos musicais, necessários no ensino de música.

\section{REFERÊNCIAS}

ADORNO, T. W. Indústria Cultural e Sociedade. São Paulo: Paz e Terra, 2002.

AMARAL, A. Manifestações da performatização do gosto nos sites de redes sociais: uma proposta pelo olhar da cultura pop. Revista ECOPós, v. 17, n. 03, 2014.

ANGROSINO, M. Etnografia e observação participante / Michael Angrosino: tradução José Fonseca: consultoria, supervisão e revisão desta edição. Bernardo Lewgoy. Porto Alegre: Artmed, 2009.

ARNAIZ, S. P. MARTÍNEZ, R. M. PEÑALVER, V. I. A Psicomotricidade na Educação Infantil: uma prática preventiva e educativa; trad. Inajara Haubert Rodrigues. Porto Alegre: Artmed, 2003.

ASSUNÇÃO, I. B. A importância do movimento corporal para a aprendizagem em fase inicial. PUCPR. 2008.

BACHMANN, M. La rítmica Jaques - Dalcroze. Una educación por la música y para la música. Madrid: Ediciones Pirámide, 1998.

BRASIL, Comitê Gestor da Internet no. Pesquisa sobre o uso das tecnologias da informação e comunicação no Brasil: TIC domicílios e empresas 2013. Coordenação executiva e editorial, Alexandre F. Barbosa; tradução. São Paulo, 2014. 
BRASIL. Lei 13.278 de 02 de maio de 2016. Altera o § 6o do art. 26 da Lei no 9.394, de 20 de dezembro de 1996, que fixa as diretrizes e bases da educação nacional, referente ao ensino da arte. Diário Oficial da União, 03 de maio de 2016.

BURGESS, J., GREEN, J. YouTube e a revolução digital : como o maior fenômeno da cultura, participativa transformou a mídia e a sociedade. São Paulo: Aleph, 2009.

CAYARI, C. The Youtube effect: How Youtube has provided ways to consume, create and share music. International Journal of Education\&Arts. v. 12, n. 6, jul. 2011. Disponível em: <www.ijea.org/v12n6/> Acesso em: 10 jun. 2016.

COSTE, Jean-Claude. A Psicomotricidade. Tradução: Álvaro Cabral, 2a ed. Rio de Janeiro: Zahar, 1978.

COTA, D. M. O Youtube e os dispositivos móveis como agentes transformadores da interação com a música. SIMPOM: Educação Musical. Anais do IV SIMPOM, 2016.

DALCROZE, Emile Jaques. Exercises de plastique animée. Paris, França: Jobin e Cie, 1916a.

Le Rythme, La musique et l'éducation. Paris, França: Jobin e Cie, 1920b.

GOES, A. Corpo percussivo e som em movimento: a prática da música corporal. Opus, Porto Alegre, v. 12, n. 1, p. 89-100, jun. 2015.

GOHN, D. Tendências na educação a distância: os softwares on-line de música. Opus, Goiânia, v. 16, n. 1, p. 113-126, jun. 2010.

KRÜGER, S. Educação musical apoiada pelas novas Tecnologias de Informação e Comunicação (TIC): pesquisas, práticas e formação de docentes. Revista da ABEM, Porto Alegre, V. 14, 75-89, mar. 2006c. 